\title{
Maternal race and intergenerational preterm birth recurrence
}

\author{
Marcela C. Smid, MD, MA, MS; Jong Hyung Lee, MS; Jacqueline H. Grant, MD; Gandarvaka Miles, MPH; \\ Gregory J. Stoddard, MPH, MBA; Derek A. Chapman, PhD; Tracy A. Manuck, MD, MSCI
}

BACKGROUND: Preterm birth is a complex disorder with a heritable genetic component. Studies of primarily White women born preterm show that they have an increased risk of subsequently delivering preterm. This risk of intergenerational preterm birth is poorly defined among Black women.

OBJECTIVE: Our objective was to evaluate and compare intergenerational preterm birth risk among non-Hispanic Black and non-Hispanic White mothers.

STUDY DESIGN: This was a population-based retrospective cohort study, using the Virginia Intergenerational Linked Birth File. All nonHispanic Black and non-Hispanic White mothers born in Virginia 1960 through 1996 who delivered their first live-born, nonanomalous, singleton infant $\geq 20$ weeks from 2005 through 2009 were included. We assessed the overall gestational age distribution between nonHispanic Black and White mothers born term and preterm $(<37$ weeks) and their infants born term and preterm ( $<37$ weeks) using Cox regression and Kaplan-Meier survivor functions. Mothers were grouped by maternal gestational age at delivery (term, $\geq 37$ completed weeks; late preterm birth, 34-36 weeks; and early preterm birth, $<34$ weeks). The primary outcomes were: (1) preterm birth among all eligible births; and (2) suspected spontaneous preterm birth among births to women with medical complications (eg, diabetes, hypertension, preeclampsia and thus higher risk for a medically indicated preterm birth). Multivariable logistic regression was used to estimate odds of preterm birth and spontaneous preterm birth by maternal race and maternal gestational age after adjusting for confounders including maternal education, maternal age, smoking, drug/alcohol use, and infant gender.

RESULTS: Of 173,822 deliveries captured in the intergenerational birth cohort, 71,676 (41.2\%) women met inclusion criteria for this study. Of the entire cohort, $30.0 \%(n=21,467)$ were non-Hispanic Black and $70.0 \%$ were non-Hispanic White mothers. Compared to non-Hispanic White mothers, non-Hispanic Black mothers were more likely to have been born late preterm (6.8\% vs $3.7 \%$ ) or early preterm (2.8 vs $1.0 \%), P<.001$. Non-Hispanic White mothers who were born (early or late) preterm were not at an increased risk of early or late preterm delivery compared to non-Hispanic White mothers born term. The risk of early preterm birth was most pronounced for Black mothers who were born early preterm (adjusted odds ratio, 3.26; 95\% confidence interval, 1.77-6.02) compared to non-Hispanic White mothers.

CONCLUSION: We found an intergenerational effect of preterm birth among non-Hispanic Black mothers but not non-Hispanic White mothers. Black mothers born $<34$ weeks carry the highest risk of delivering their first child very preterm. Future studies should elucidate the underlying pathways leading to this racial disparity.

Key words: health disparity, intergenerational recurrence, perinatal epidemiology, preterm birth, racial disparity

\section{Introduction}

Preterm birth, defined as delivery $<37$ weeks' gestation, is a leading cause of infant morbidity and accounts for 36\% of infant mortality in the United States. ${ }^{1,2}$ Preterm birth is a significant public health challenge with annual hospitalization costs of $\$ 5.8$ billion. ${ }^{3}$ However, the burden of preterm birth is not equally distributed among populations. In 2015, the overall preterm birth rate in the United States was 9.6\%; however, the $13.4 \%$ preterm birth rate among non-Hispanic Black women was $50 \%$ higher than among non-Hispanic
White women $(8.9 \%) .^{2}$ In 2014 , for the first time since 2007, the annual preterm birth rate increased and the disparity between non-Hispanic Black and nonHispanic White women widened.

The etiology of racial disparities in preterm birth in the United States is most likely an intersection of sociodemographic factors, maternal health behaviors, environmental exposure, access to care, and genetic predisposition. ${ }^{4-9}$ Intergenerational studies of preterm birth risk may provide clues to the complex relationship of these risk factors, ${ }^{10-16}$ but few have included Black women. ${ }^{17-19}$ To date, these studies show conflicting results. Several large population-based studies conducted in Sweden and Denmark failed to demonstrate a preterm birth intergenerational effect. ${ }^{16,20}$ A large population-based study in Illinois found an intergenerational association for preterm birth for non-Hispanic Black women, but not non-Hispanic White women. ${ }^{19}$ Other intergenerational studies of primarily White women demonstrate an inverse relationship between the odds of preterm birth and maternal gestational age at birth. ${ }^{10,12-14}$ Two studies, one which included Black women, demonstrated that intergenerational recurrences of preterm birth were higher if mothers were born late preterm (34-36 weeks); the risk further increases if mothers are born early preterm $(<34$ weeks) compared to women born at term. ${ }^{11,17}$ Previous limited studies of gestational age distributions in the United States suggest that Black infants are born earlier than White infants. ${ }^{21,22}$ However, these studies do not report the risk of spontaneous preterm birth or intergenerational gestational age distribution among Black and White women.

Therefore, the objective of this study was to investigate intergenerational recurrence 


\section{FIGURE 1}

\section{Study cohort selection of mother-infant pairs from the Virginia Intergenerational Linked Birth File $(n=71,667)$}

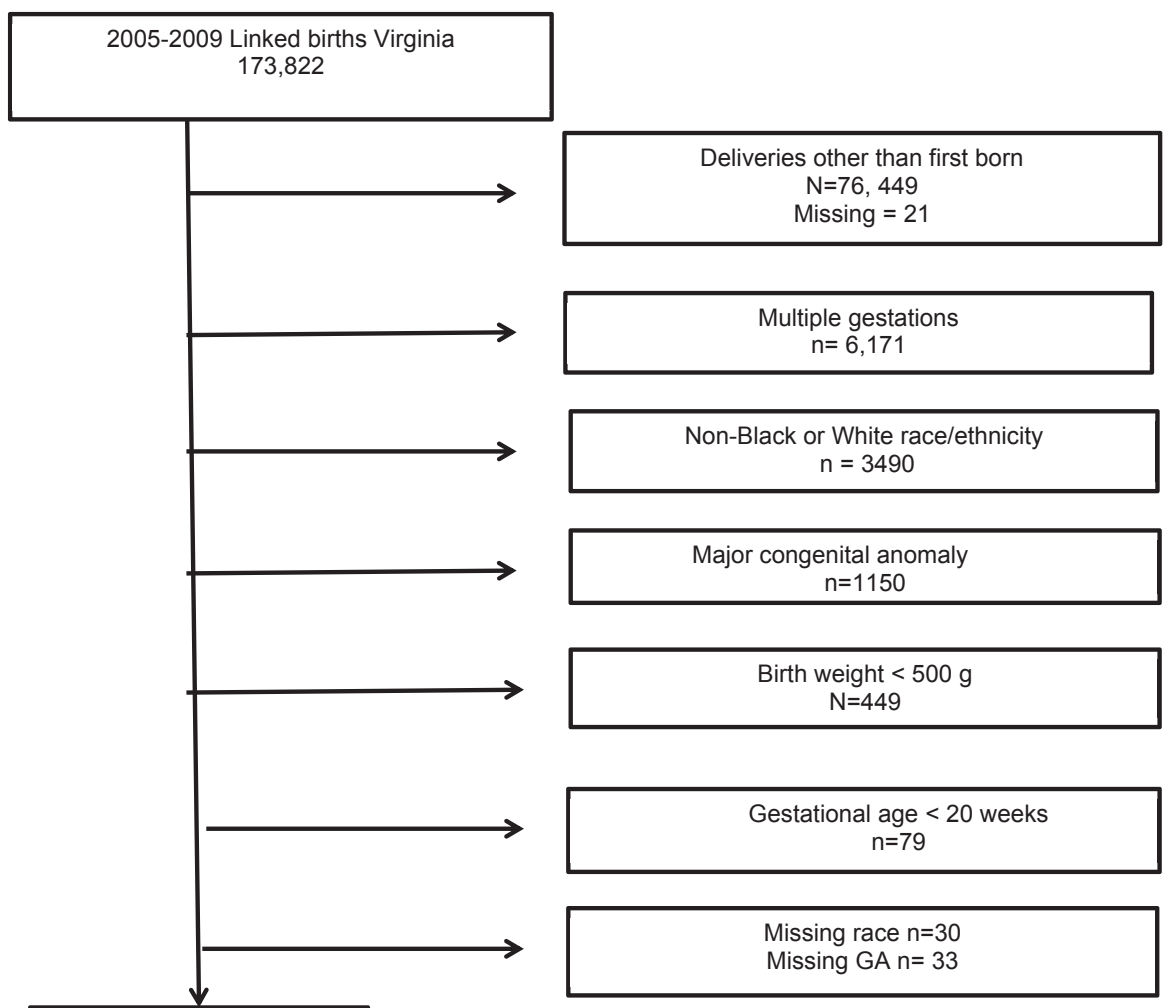

Final data

$\mathrm{N}=71,676$

Study cohort selection of mother-infant pairs from Virginia Intergenerational Linked Birth File ( $\mathrm{n}=71,667)$.

$G A$, gestational age.

Smid et al. Maternal race and intergenerational preterm birth. Am J Obstet Gynecol 2017.

of preterm birth among non-Hispanic Black and White mothers. We aimed to compare the risk of spontaneous preterm birth and the gestational age distribution among non-Hispanic Black and White mothers and their infants born term and preterm. We hypothesized that due to the higher risk of preterm birth in the nonHispanic Black population, non-Hispanic Black mothers have increased intergenerational preterm birth transmission and earlier gestational age distribution of both themselves and their infants compared to non-Hispanic White mothers.

\section{Materials and Methods}

\section{Study population}

We conducted a population-based retrospective cohort study using the linkage rate of transgenerational data sets for a US population.

For our study, linked birth records for all deliveries $\geq 20$ weeks' gestation for non-Hispanic Black and White mothers born from 1960 through 1997 who resided in Virginia and delivered their first live-born singleton infants from 2005 through 2009 were included. Due to small numbers, women of other racial/ethnic groups were excluded $(\mathrm{n}=3490)$. Mother-infant pairs were also excluded if the delivery was not of the firstborn infant $(76,449)$, pregnancy was a multifetal gestation $(\mathrm{n}=6171)$, infant had severe congenital anomalies or aneuploidy (eg, anencephaly, spina bifida, heart malformations, trisomy 21) ( $n=1150)$, infant's gestational age at delivery was $<20$ weeks $(n=79)$, or the birthweight was $<500 \mathrm{~g}(\mathrm{n}=449)$ or was missing $(\mathrm{n}=54)$ (Figure 1$)$. Because we report the number of women with each exclusion criteria and some women had multiple exclusions, the sum of women meeting each exclusion criteria is greater than the total number of women excluded $(\mathrm{n}=102,146)$.

The Institutional Review Board (IRB) at the Virginia Department of Health and Virginia Commonwealth University deemed this study exempt from review due to the deidentified nature of this data set.

\section{Exposure}

Virginia Intergenerational Linked Birth File. This database was created by linking Virginia resident live birth certificate data: maternal information from 2005 through 2009 to infant information from 1960 through 1997. The details of this data set were previously published. ${ }^{23}$ Briefly, building on the methods used to develop the Washington State Intergenerational Study of Birth Outcomes ${ }^{24}$ and the Illinois Transgenerational Data Set, ${ }^{19}$ the Virginia Intergenerational Linked Birth File is the largest linked birth data set available for US populations. By additionally assessing for minor spelling mistakes in mother and infant's names, $87 \%$ of eligible births were linked, representing the highest
Our exposure was maternal gestational age at delivery. Gestational age was based on the number of completed weeks' gestation recorded in the birth certificate data. Methods for assessing gestational age varied over the study period: last menstrual period dating was exclusively used from 1960 through 1978 while clinical estimate of gestation was also recorded for births occurring after 1978. We used the method of gestational age dating (last menstrual period or clinical), which was used for the pregnancy and recorded on the birth certificate. Mothers' gestational age at delivery was grouped into 3 clinically relevant categories: term birth $(\geq 37$ completed weeks' gestation); late preterm birth (34-36 completed weeks' gestation); and 
TABLE 1

Maternal, clinical, and delivery characteristics of non-Hispanic White and Black women born term ( $\geq 37$ weeks), late preterm (34-36 weeks), and early preterm ( $<34$ weeks) of firstborn singletons in Virginia Intergenerational Linked Birth File $(n=71,676)$

\begin{tabular}{|c|c|c|c|c|c|c|c|}
\hline \multirow[b]{5}{*}{ Maternal characteristics } & \multicolumn{3}{|c|}{$\begin{array}{l}\text { Non-Hispanic White mothers } \\
N=50,209\end{array}$} & \multicolumn{3}{|c|}{$\begin{array}{l}\text { Non-Hispanic Black mothers } \\
\mathrm{N}=21,467\end{array}$} & \multirow[b]{5}{*}{$P$ value $^{\mathrm{a}}$} \\
\hline & \multicolumn{6}{|c|}{ Gestational age of maternal delivery } & \\
\hline & \multirow{2}{*}{$\begin{array}{l}\geq 37 \text { wk } \\
\mathrm{N}(\%)\end{array}$} & \multirow{2}{*}{$\frac{34-36 \mathrm{wk}}{\mathrm{N}(\%)}$} & \multirow{2}{*}{$\frac{<34 \text { wk }}{\mathrm{N}(\%)}$} & \multirow{2}{*}{$\frac{\geq 37 \mathrm{wk}}{\mathrm{N}(\%)}$} & \multirow{2}{*}{$\frac{34-36 \mathrm{wk}}{\mathrm{N}(\%)}$} & \multirow{2}{*}{$\frac{<34 \mathrm{wk}}{\mathrm{N}(\%)}$} & \\
\hline & & & & & & & \\
\hline & $47,888\left(95.4^{b}\right)$ & $1846\left(3.7^{b}\right)$ & $475\left(1.0^{\mathrm{b}}\right)$ & $19,424\left(90.5^{b}\right)$ & $1450\left(6.8^{b}\right)$ & $593\left(2.8^{b}\right)$ & \\
\hline Maternal age, y & & & & & & & $<.0001^{\mathrm{C}}$ \\
\hline$<19$ & $5286(11.0)$ & $246(13.3)$ & $53(11.2)$ & $5099(26.3)$ & $394(27.2)$ & $133(22.4)$ & \\
\hline $19-34$ & $39,674(82.9)$ & $1485(80.4)$ & 395 (83.2) & $13,760(70.8)$ & $1015(70.0)$ & $440(74.2)$ & \\
\hline$\geq 35$ & $2928(6.1)$ & $115(6.2)$ & $27(5.7)$ & $565(2.9)$ & $41(2.8)$ & $20(3.4)$ & \\
\hline Insurance, n (\%) & & & & & & & $<.0001^{\mathrm{C}}$ \\
\hline Medicaid & $13,211(27.6)$ & $592(32.1)$ & $173(36.4)$ & $10,098(52.0)$ & $794(54.8)$ & $328(55.3)$ & \\
\hline Private & $33,387(69.7)$ & $1186(64.3)$ & $289(60.8)$ & $8539(44.0)$ & $590(40.7)$ & $232(39.1)$ & \\
\hline Self-pay & $982(2.1)$ & $55(3.0)$ & $13(2.7)$ & $737(3.8)$ & $60(4.1)$ & $29(4.9)$ & \\
\hline Missing & $308(0.6)$ & $13(0.7)$ & - & $50(0.3)$ & $6(0.4)$ & $4(0.7)$ & \\
\hline Education, n (\%) & & & & & & & $<.0001^{\mathrm{C}}$ \\
\hline$<$ High school & 4931 (10.3) & $233(12.6)$ & $67(14.1)$ & 4809 (24.8) & $376(25.9)$ & $135(22.8)$ & \\
\hline High school & $18,374(38.4)$ & $728(39.4)$ & $215(45.3)$ & 8415 (43.3) & $678(46.8)$ & $299(50.4)$ & \\
\hline College & $24,204(50.5)$ & $867(47.0)$ & $192(40.4)$ & $6082(31.3)$ & $386(26.6)$ & $156(26.3)$ & \\
\hline Unknown & $379(0.8)$ & $18(1.0)$ & $1(0.2)$ & $118(0.6)$ & $10(0.7)$ & $3(0.5)$ & \\
\hline Married, n (\%) & $28,186(58.9)$ & $987(53.5)$ & $248(52.2)$ & 2704 (13.9) & $163(11.2)$ & $68(11.5)$ & $<.0001^{\mathrm{C}}$ \\
\hline $\begin{array}{l}\text { Any maternal } \\
\text { comorbidity, } \mathrm{n}(\%)\end{array}$ & $13,592(28.4)$ & $547(29.6)$ & $149(31.4)$ & 6522 (33.6) & 491 (33.9) & $208(35.1)$ & $<.0001^{\mathrm{C}}$ \\
\hline Smoking, n (\%) & $5028(10.5)$ & $219(11.9)$ & $70(14.7)$ & $948(4.9)$ & $69(4.8)$ & $27(4.6)$ & $<.0001^{\mathrm{c}}$ \\
\hline Alcohol, n (\%) & $219(0.5)$ & $2(0.1)$ & $2(0.4)$ & $59(0.3)$ & $4(0.3)$ & $1(0.2)$ & $.0347^{d}$ \\
\hline Any drugs, $\mathrm{n}(\%)$ & $494(1.0)$ & $14(0.8)$ & $7(1.5)$ & 241 (1.2) & $18(1.2)$ & $11(1.9 \%)$ & $.0435^{\mathrm{d}}$ \\
\hline
\end{tabular}




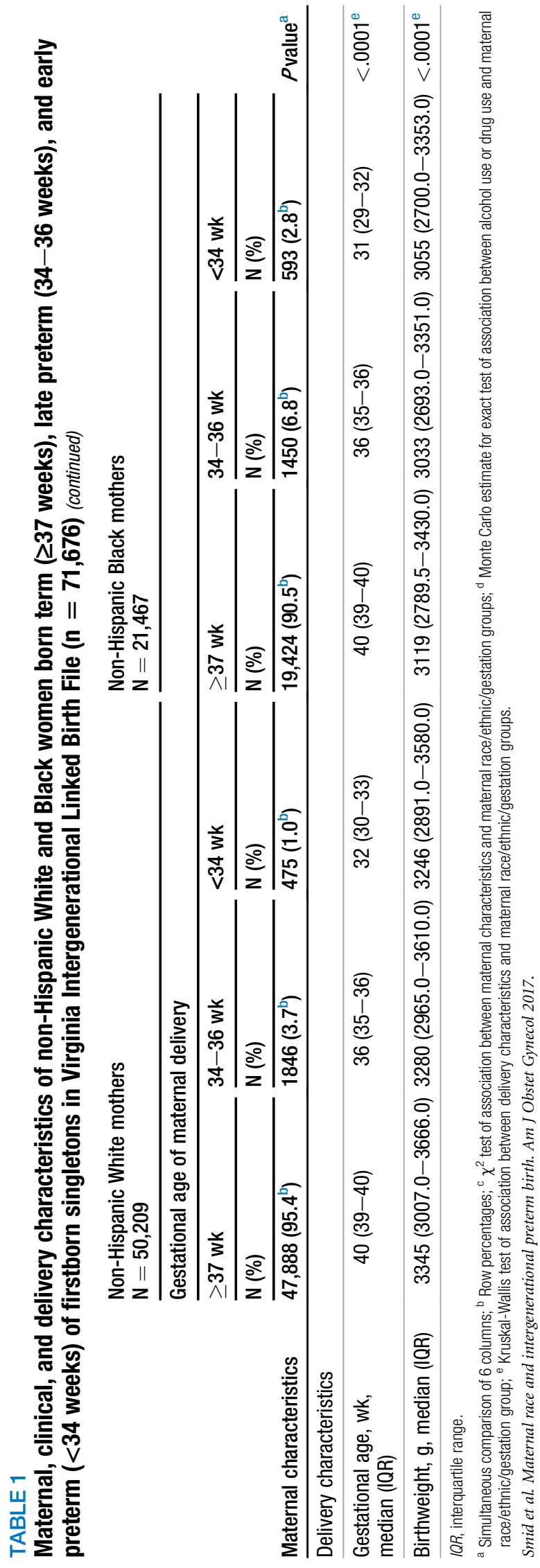

early preterm birth (delivery $<34$ completed weeks' gestation).

\section{Outcomes}

The primary outcome was gestational age at delivery of the mother's firstborn infant. We grouped infant delivery gestational age into 3 clinically relevant categories as described above (term, late preterm birth, early preterm birth). Our secondary outcome was spontaneous preterm birth $<37$ weeks' gestation. Because preterm etiologies (eg, spontaneous, indicated) were not differentiated in the Virginia Intergenerational Linked Birth File, we defined a surrogate spontaneous preterm birth variable. Motherinfant pairs in which the mother did not have medical comorbidities or pregnancy complications associated with an increased risk of indicated preterm birth were considered spontaneous preterm birth. These medical comorbidities and pregnancy complications included maternal cardiac disease, pregestational and gestational diabetes, hydramnios/ oligohydramnios, chronic hypertension, gestational hypertension, eclampsia, renal disease, placenta previa, and $\mathrm{Rh}$ sensitization. ${ }^{25-28}$

\section{Statistical analysis}

Maternal and delivery characteristics were compared across maternal racial and gestational age groups using the $\chi^{2}$ test, Fisher exact test, or Kruskal-Wallis analysis of variance, as appropriate. Since the sample size of this study and the dimension of the frequency table for some predictor variables was large, the Monte Carlo estimate for Fisher exact test was applied, as appropriate.

Kaplan-Meier survival curves were used to evaluate the gestational age at delivery between non-Hispanic Black and non-Hispanic White mothers and their infants, and were compared with the log-rank test. We created separate curves for mothers and for infants to evaluate the distribution of birth gestational age. Cox regression models were then used to calculate hazard ratios of gestational weeks at delivery between non-Hispanic Black and non-Hispanic White mothers and their infants born term and preterm. In this analysis, we 


\section{TABLE 2}

Mean delivery gestational age and hazard ratios for earlier delivery by completed gestational weeks for non-Hispanic Black and White mother and infants born preterm ( $<37$ weeks) and at term ( $\geq 37$ weeks)

\begin{tabular}{|c|c|c|c|}
\hline & Non-Hispanic Black & Non-Hispanic White & \\
\hline Group & $\begin{array}{l}\text { Gestational age, } \\
\text { wk, mean } \pm \text { SD }\end{array}$ & $\begin{array}{l}\text { Gestational age, } \\
\text { wk, mean } \pm \text { SD }\end{array}$ & Hazard ratio $(95 \% \mathrm{Cl})$ \\
\hline Mother born preterm & $34.0 \pm 2.6$ & $34.6 \pm 2.1$ & $1.14(1.08-1.22)$ \\
\hline Mother born term & $39.6 \pm 1.2$ & $39.8 \pm 1.1$ & $1.12(1.11-1.14)$ \\
\hline Infant born preterm & $32.8 \pm 4.0$ & $33.9 \pm 2.9$ & $1.18(1.13-1.24)$ \\
\hline Infant born term & $39.0 \pm 1.1$ & $39.2 \pm 1.1$ & $1.09(1.07-1.10)$ \\
\hline
\end{tabular}

Cl, confidence interval.

All $P<.001$

Smid et al. Maternal race and intergenerational preterm birth. Am J Obstet Gynecol 2017.

began the follow-up at 20 weeks' gestational age to avoid immortal time bias. Less than 20 weeks represented immortal time, in which preterm birth events could not occur, since by study design we excluded deliveries $<20$ weeks.

In analyses where data are displayed using a predictor variable based on gestational age categories, Cox regression is not applicable, as time is both an outcome and a predictor in the model, so we used a logistic regression approach. Specifically, multivariable logistic regression was used to compare the intergenerational odds of preterm birth and spontaneous preterm birth after adjusting for confounders. Confounders were selected a priori and included maternal education, maternal age, smoking, drug/alcohol use, and infant gender. In all models, non-Hispanic White mothers born at term were the reference group.

For all analyses, 2-tailed 95\% confidence interval (CI) and $P$ values were examined. Analyses were performed using software (SAS, Version 9.4; SAS Institute Inc, Cary, NC).

\section{Results}

There were 173,822 mother-infant pairs included in the Virginia intergenerational birth cohort. Of these, 71,676 $(41.2 \%)$ women met the study inclusion criteria. In the analysis sample $30.0 \%$ of mothers $(\mathrm{n}=21,467)$ were non-Hispanic Black and $70.0 \%$ were non-Hispanic White. Compared to
non-Hispanic White mothers, nonHispanic Black mothers were younger, more likely to have had their delivery paid for by Medicaid and less likely to be married (all $P<.0001$ ) (Table 1). NonHispanic Black mothers were also more likely to have a maternal comorbidity and/or a pregnancy complication but less likely to smoke during pregnancy compared to non-Hispanic White

mothers (Table 1). The mean gestational ages of non-Hispanic Black mothers and infants born preterm were earlier compared to non-Hispanic White mothers and infants born preterm (Table 2). These trends persisted when examining the gestational age of only those mothers born at term. KaplanMeier survival analyses demonstrated that the earlier delivery gestational age

\section{FIGURE 2}

\section{Survival curve for Non-Hispanic Black and White mothers $(n=4364)$ born preterm $<37$ weeks, log rank $P<0.001$}

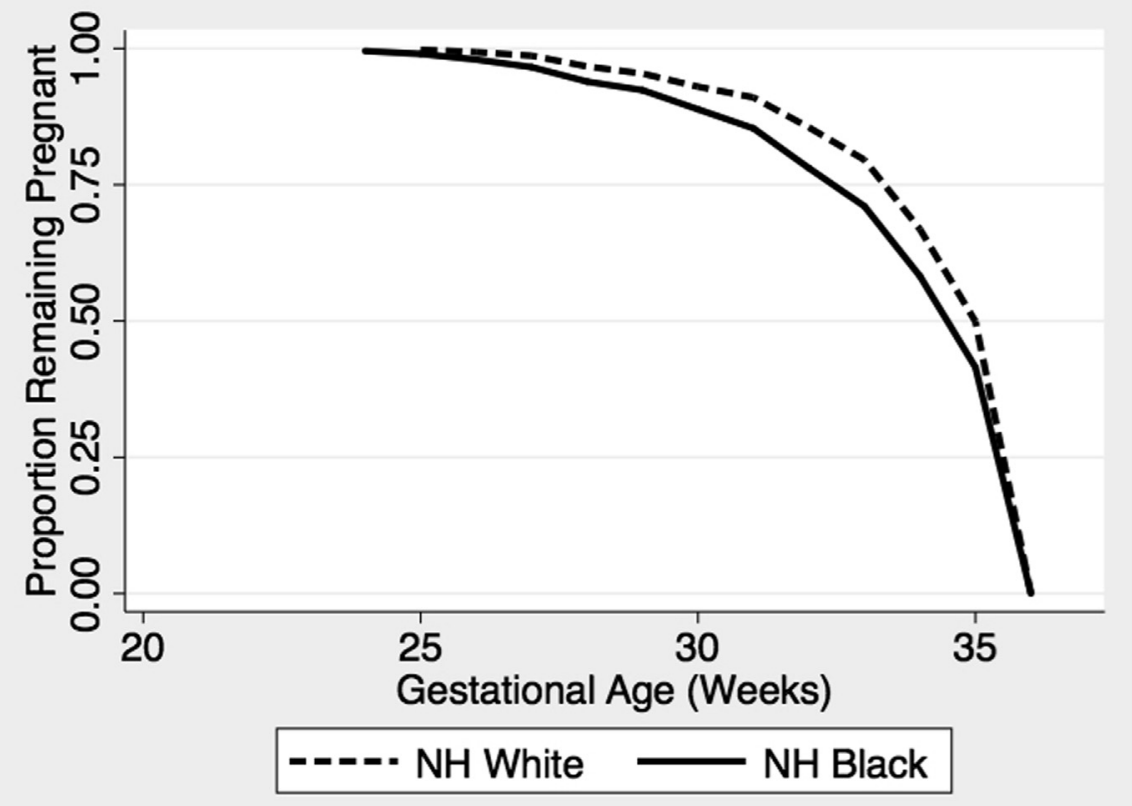

Survival curve for non-Hispanic (NH) Black and White mothers $(n=4364)$ born preterm $<37$ weeks, log rank $P<.001$.

Smid et al. Maternal race and intergenerational preterm birth. Am J Obstet Gynecol 2017. 


\section{FIGURE 3}

\section{Survival curve for NH Black and White infants $(n=6831)$ born preterm, log rank $P<0.001$}

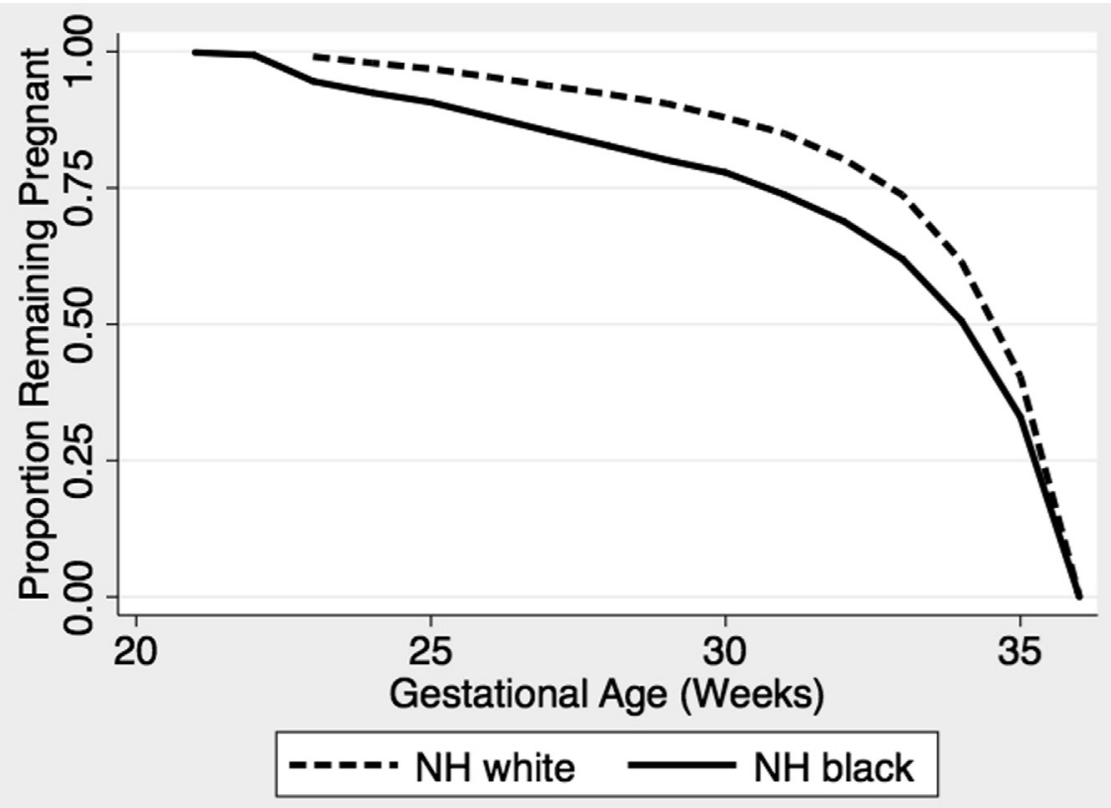

Survival curve for non-Hispanic $(\mathrm{NH})$ Black and White infants $(\mathrm{n}=6831)$ born preterm, log rank $P<.001$.

Smid et al. Maternal race and intergenerational preterm birth. Am J Obstet Gynecol 2017.

among non-Hispanic Blacks was constant across all gestational ages for both mother and infants; differences in gestational age distribution were most pronounced among infants delivered preterm (Figures 2 and 3 ).

Overall, 2043 (9.5\%) of non-Hispanic Black mothers and 2321 (4.6\%) of nonHispanic White mothers were born preterm $(P<.001)$ (Table 3$)$. Infants born to non-Hispanic Black mothers were also more likely to be preterm compared to those born to nonHispanic White mothers ( $11.6 \%$ vs 8.6 , respectively, $P<.001)$, regardless of maternal gestational age at delivery. The severity of maternal preterm birth was associated with increased severity of infant's preterm birth. Among all mothers included in our cohort, non-Hispanic Black mothers who were born early preterm had the highest prevalence of infants born early preterm (5.9\%). In the unadjusted analysis, non-Hispanic White mothers who were born preterm and all non-Hispanic Black women, including those born term, had increased odds of having an early preterm infant (Table 4). However, after adjustment for confounders, only nonHispanic Black mothers had increased odds of an early preterm infant. The odds of having an early preterm infant was most pronounced for non-Hispanic Black mothers who themselves were born early preterm $<34$ weeks (adjusted odds ratio $[\mathrm{aOR}], 3.26 ; 95 \% \mathrm{CI}$, 1.77-6.02) compared to non-Hispanic White women who were born term. In contrast, no significant intergenerational effect was seen among non-Hispanic White women. When we assessed the odds of intergenerational recurrence of spontaneous preterm, results were similar to the overall cohort (Table 5).

\section{Comment}

In this large cohort of mother-infant pairs born in Virginia, we found an intergenerational effect of preterm birth among non-Hispanic Black women but not non-Hispanic White women. NonHispanic Black mothers and infants had a shifted, earlier delivery gestational age compared to non-Hispanic White mothers and infants, regardless of whether delivery was term or preterm. These intergenerational effects were dose-dependent: non-Hispanic Black mothers born early preterm carried the highest risk of delivering their first child early preterm.

Our study is one of a few focusing on racial disparity in intergenerational preterm birth. In a recent study of non-Hispanic Black $(\mathrm{n}=1667)$ and nonHispanic White $(\mathrm{n}=4384)$ motherinfant pairs in Allegheny County of Pennsylvania, Ncube et $\mathrm{al}^{17}$ found that non-Hispanic Black women born preterm were more likely to deliver preterm (aOR, 1.63; 95\% CI, 1.10-12.43) and late preterm (aOR, 1.68; 95\% CI, 1.07-2.64) but not early preterm (aOR, 1.47; 95\% CI, 0.69-3.12) compared to non-Hispanic Black women born term. In contrast to the study of Ncube et al, ${ }^{17}$ which provided a stratified analysis by maternal race, we compared non-Hispanic Black women to non-Hispanic White women in our models to characterize racial disparity in intergenerational preterm birth. Additionally, our study is larger and includes birth data for mother-infant pairs who were both born within the entire state of Virginia including in rural, suburban, and urban areas. In an intergenerational linked birth file of non-Hispanic White $(\mathrm{n}=110,338)$ and non-Hispanic Black ( $\mathrm{n}=32,986)$ mother-infant pairs in Illinois, Castrillio et $\mathrm{al}^{19}$ also found no intergenerational preterm recurrence risk among non-Hispanic White women. Among non-Hispanic Black women, there was an inconsistent risk of preterm birth compared to non-Hispanic women born at term. The study of Castrillio et $\mathrm{al}^{19}$ also included all deliveries, not only firstborns, and adjusted for parity. However, other studies have shown that overall gestational age decreases with subsequent deliveries; therefore, this trend may impact the intergenerational effect of each subsequent delivery differently among White and Black women. ${ }^{10,29}$ For this reason, we restricted our sample to only firstborn infants.

Our study has several strengths. With $>70,000$ mother-infant pairs, our study included a large number of 


\section{TABLE 3}

Proportion of non-Hispanic Black and White mothers born term ( $\geq 37$ weeks), late preterm (34-36 weeks), and early preterm ( $<34$ weeks) who delivered their firstborn infants term ( $\geq 37$ weeks), late preterm (34-36 weeks), and early preterm $(<34$ weeks) in Virginia Intergenerational Linked Birth File $(n=71,676)$

\begin{tabular}{|c|c|c|c|c|c|c|c|c|}
\hline \multirow{4}{*}{$\begin{array}{l}\text { Gestational } \\
\text { age of } \\
\text { firstborn infant }\end{array}$} & \multicolumn{4}{|c|}{$\begin{array}{l}\text { Non-Hispanic White mothers } \\
N=50,209\end{array}$} & \multicolumn{4}{|c|}{$\begin{array}{l}\text { Non-Hispanic Black mothers } \\
N=21,467\end{array}$} \\
\hline & \multicolumn{8}{|c|}{ Gestational age of maternal delivery } \\
\hline & $\begin{array}{l}\geq 37 \text { wk } \\
n=47,882\end{array}$ & $\begin{array}{l}34-36 \text { wk } \\
n=1846\end{array}$ & $\begin{array}{l}<34 \text { wk } \\
\mathrm{n}=475\end{array}$ & & $\begin{array}{l}\geq 37 \text { wk } \\
n=19,421\end{array}$ & $\begin{array}{l}34-36 \text { wk } \\
n=1450\end{array}$ & $\begin{array}{l}<34 \text { wk } \\
n=593\end{array}$ & \\
\hline & $\mathrm{n}(\%)$ & $\mathrm{n}(\%)$ & $\mathrm{n}(\%)$ & $P$ value & $\mathrm{n}(\%)$ & $\overline{n(\%)}$ & $\mathrm{n}(\%)$ & $P$ value \\
\hline$\geq 37$ wk & $43,787(91.4)$ & $1657(89.8)$ & $418(88.0)$ & $.0002^{\mathrm{a}}$ & $17,210(88.6)$ & $1248(86.1)$ & $516(87.0)$ & $.0801^{b}$ \\
\hline $34-36$ wk & $3025(6.3)$ & $124(6.7)$ & $35(7.4)$ & & $1421(7.3)$ & $128(8.8)$ & $42(7.1)$ & \\
\hline$<34$ wk & $1070(2.2)$ & $65(3.5)$ & $22(4.6)$ & & $790(4.1)$ & $74(5.1)$ & $35(5.9)$ & \\
\hline
\end{tabular}

non-Hispanic Black and non-Hispanic White mothers and their firstborn infants. Other studies have also shown that birth order is associated with a decrease in gestational age at delivery, particularly among women with a prior preterm birth. ${ }^{29,30}$ Because prior spontaneous preterm birth is the strongest risk for preterm birth, ${ }^{4}$ we chose to include only firstborn infants to reduce confounding by earlier gestation with subsequent pregnancies. In contrast to some of the other intergenerational studies, we were able to evaluate more thoroughly for dose-dependent associations by including women who were born $<34$ weeks' gestation.

Our study has some notable limitations. Our study is reliant on the quality of data recorded on the birth certificate. Studies using birth certificate data sets suggest that elements related to gravidity, maternal race, gestational age at delivery, and adverse pregnancy outcomes have high sensitivity; however, maternal medical conditions are often missing or inaccurate. ${ }^{31-34}$ In our data set, there were no missing data for maternal age; $<1 \%$ of women included in this cohort had missing information for maternal education, smoking, drug/alcohol use, infant gender, and maternal medical conditions. With respect to maternal medical conditions, the risk of misclassification bias is probable with any studies derived from birth certificate data sets, our results should be interpreted with caution. Because the linkage was based solely on Virginia births, linked mother-infant pairs were limited to mothers born in Virginia who resided in Virginia at the time they gave birth to their first child. A combination of factors such as migration to the United States or across states and a smaller population

\section{TABLE 4 \\ Unadjusted and adjusted odds ratios and $95 \%$ confidence interval of delivery of preterm delivery ( $<37$ weeks) of firstborn singleton infants among non-Hispanic Black and White mothers in Virginia Intergenerational Linked Birth File $(n=71,667)$}

\begin{tabular}{|c|c|c|c|c|}
\hline Mothers by GA at delivery & $\begin{array}{l}\text { Preterm infant } \\
<34 \text { wk } \\
\text { Unadjusted OR (95\% Cl) }\end{array}$ & $\begin{array}{l}\text { Preterm infant } \\
<34 \text { wk } \\
\text { Adjusted OR }(95 \% \mathrm{Cl})^{\mathrm{a}}\end{array}$ & $\begin{array}{l}\text { Preterm infant } 34-36 \text { wk } \\
\text { Unadjusted OR }(95 \% \mathrm{CI})\end{array}$ & $\begin{array}{l}\text { Preterm infant } \\
34-36 \text { wk } \\
\text { Adjusted OR }(95 \% \mathrm{Cl})^{\mathrm{a}}\end{array}$ \\
\hline NH White born $\geq 37$ wk & 1.00 & 1.00 & 1.00 & 1.00 \\
\hline NH White born $34-36$ wk & $1.61(1.24-2.07)^{b}$ & $1.28(0.71-2.31)$ & $1.08(0.90-1.31)$ & $1.03(0.68-1.54)$ \\
\hline NH White born $<34$ wk & $2.15(1.40-3.32)^{b}$ & $2.02(0.81-5.02)$ & $1.21(0.86-1.72)$ & $1.07(0.50-2.33)$ \\
\hline NH Black born $\geq 37$ wk & $1.88(1.71-2.06)^{b}$ & $1.81(1.48-2.22)^{b}$ & $1.20(1.12-1.28)^{b}$ & $1.26(1.10-1.45)^{b}$ \\
\hline NH Black born 34-36 wk & $2.43(1.91-3.09)^{b}$ & $2.00(1.24-3.22)^{b}$ & $1.49(1.23-1.79)^{b}$ & $1.47(1.03-2.10)^{b}$ \\
\hline NH Black born $<34$ wk & $2.78(1.96-3.93)^{b}$ & $3.26(1.77-6.02)^{b}$ & $1.18(0.86-1.62)$ & $1.10(0.57-2.11)$ \\
\hline
\end{tabular}

$\mathrm{Cl}$, confidence interval; $\mathrm{GA}$, gestational age; $\mathrm{NH}$, non-Hispanic; $\mathrm{OR}$, odds ratio.

${ }^{a}$ Adjusted for maternal education, maternal age, smoking, drug/alcohol use, and infant gender; ${ }^{b}$ Statistical significance, $P<.05$.

Smid et al. Maternal race and intergenerational preterm birth. Am J Obstet Gynecol 2017. 


\section{TABLE 5 \\ Unadjusted and adjusted odds ratios and 95\% confidence interval of delivery of spontaneous preterm delivery ( $<37$ weeks) of firstborn singleton infants among non-Hispanic Black and White mothers in Virginia Intergenerational Linked Birth File $(n=63,116)$}

\begin{tabular}{lllll} 
Mothers by GA at delivery & $\begin{array}{l}\text { Preterm infant }<34 \text { wk } \\
\text { Unadjusted OR }(95 \% \mathrm{Cl})\end{array}$ & $\begin{array}{l}\text { Preterm infant }<34 \text { wk } \\
\text { Adjusted OR } \mathbf{R}^{\mathrm{b}}(95 \% \mathrm{Cl})\end{array}$ & $\begin{array}{l}\text { Preterm infant 34-36 wk } \\
\text { Unadjusted 0R }(95 \% \mathrm{Cl})\end{array}$ & $\begin{array}{l}\text { Preterm infant 34-36 wk } \\
\text { Adjusted OR }\end{array}$ \\
\hline NH White born $\geq 37$ wk & 1.00 & 1.00 & 1.00 & 1.00 \\
\hline NH White born $34-36$ wk) & $1.54(1.14-2.08)^{\mathrm{a}}$ & $1.34(0.70-2.56)$ & $1.05(0.85-1.30)$ & $0.89(0.55-1.45)$ \\
\hline NH White born $<34$ wk) & $2.39(1.48-3.86)^{\mathrm{a}}$ & $2.07(0.75-5.74)$ & $1.19(0.80-1.77)$ & $0.99(0.40-2.45)$ \\
\hline NH Black born $\geq 37$ wk & $1.93(1.74-2.15)^{\mathrm{a}}$ & $1.78(1.42-2.22)^{\mathrm{a}}$ & $1.17(1.09-1.26)^{\mathrm{a}}$ & $1.19(1.02-1.40)^{\mathrm{a}}$ \\
\hline NH Black born $34-36$ wk & $2.69(2.07-3.50)^{\mathrm{a}}$ & $1.87(1.10-3.18)^{\mathrm{a}}$ & $1.67(1.37-2.04)^{\mathrm{a}}$ & $1.52(1.04-2.22)^{\mathrm{a}}$ \\
\hline NH Black born $<34$ wk & $3.14(2.15-4.60)^{\mathrm{a}}$ & $3.30(1.69-6.43)^{\mathrm{a}}$ & $1.19(0.83-1.71)$ & $1.06(0.51-2.19)$ \\
\hline
\end{tabular}

$\mathrm{Cl}$, confidence interval; $\mathrm{GA}$, gestational age; $\mathrm{NH}$, non-Hispanic; $O R$, odds ratio.

${ }^{a}$ Statistical significance, $P<.05 ;{ }^{b}$ Adjusted for maternal education, maternal age, smoking, drug/alcohol use, and infant gender.

Smid et al. Maternal race and intergenerational preterm birth. Am J Obstet Gynecol 2017.

size in the state precluded the study of racial/ethnic groups other than nonHispanic Black and non-Hispanic White mother-infant pairs. Additionally, we did not have information regarding paternal gestational age at delivery. However, in a Norwegian study of paternal-maternal-infant triads, the maternal contribution to intergenerational preterm birth was much stronger than the paternal contribution. ${ }^{13}$ We were also limited by the information available on the Virginia birth certificates during the study period. Both very high maternal body mass index (BMI) $\left(\geq 40 \mathrm{~kg} / \mathrm{m}^{2}\right)$ and very low maternal BMI $\left(<18.5 \mathrm{~kg} / \mathrm{m}^{2}\right)$ are risk factors for preterm birth. ${ }^{35-37}$ During our study period for the maternal cohort, prepregnancy BMI was not available on the Virginia birth certificate. Finally, a key missing component in the epidemiology of intergenerational preterm recurrence is differentiation between spontaneous vs indicated preterm birth. The 2003 US Standard Certificate of Live Birth provides expanded details about delivery, including providing sufficient details to differentiate between spontaneous vs indicated preterm delivery. ${ }^{38}$ However, during the time period of this study, Virginia had not adopted the revised birth certificate. We created a surrogate for spontaneous preterm birth by excluding mother-infant pairs with any maternal medical comorbidity or pregnancy complication from our spontaneous preterm birth analysis. In the United States, it is difficult to accurately determine spontaneous preterm birth on a large scale, thus we propose this approach when considering large birth certificate data sets in the United States prior to 2003. Previous algorithms have attempted to determine accurate methodology to differentiate spontaneous vs provider-indicated preterm birth. ${ }^{39}$ Our methodology approximates previously published approaches, ${ }^{39}$ although modified based on the variables that were available. Furthermore, even with chart review, disagreement regarding the indication for preterm delivery occurs in $10-15 \%$ of cases. ${ }^{40,41}$ While our measure of spontaneous preterm birth analysis is not validated by medical records or other birth certificate data, our broad definition biases our results toward the null as not all medical comorbidities or pregnancy complications will lead to indicated preterm delivery.

Finally, in 2005, the United States had an overall preterm birth rate of $12.7 \%$; $11.7 \%$ for non-Hispanic White mothers and $18.7 \%$ for non-Hispanic Black mothers. In 2005, Virginia had an overall preterm birth rate of $11.2 \%$; $11.7 \%$ for non-Hispanic White mothers and $16.7 \%$ for non-Hispanic Black mothers. ${ }^{42}$ It is also possible that our overall low preterm birth rate may be due to underclassification or a true reflection of the specific transgenerational population we are studying.

Our study contributes to the mounting evidence of racial differences in intergenerational preterm birth. We, and others, speculate that this racial disparity in intergenerational preterm may be related to genetic or epigenetic changes in genes involved in cardiovascular, metabolic, and immune pathways found among non-Hispanic Black women who delivered preterm. $^{43,44}$ Future studies should examine the role of sociodemographic characteristics, access to care, and epigenetic changes in the pathways that lead to racial differences in intergenerational preterm birth. One day, elucidating these pathways may lead to targeting interventions that prevent intergenerational transmission of preterm birth risk.

\section{References}

1. McCormick MC. The contribution of low birth weight to infant mortality and childhood morbidity. N Engl J Med 1985;312:82-90.

2. Martin JA, Hamilton BE, Osterman MJ. Births in the United States, 2015. NCHS Data Brief 2016:1-8

3. Russell RB, Green NS, Steiner CA, et al. Cost of hospitalization for preterm and low birth weight infants in the United States. Pediatrics 2007;120:e1-9.

4. Goldenberg RL, Culhane JF, lams JD, Romero R. Epidemiology and causes of preterm birth. Lancet 2008;371:75-84. 
5. Institute of Medicine Committee on Understanding Premature Birth and Assuring Healthy Outcomes. In: Behrman RE, Butler AS, eds. Preterm birth: causes, consequences, and prevention. Washington (DC): National Academies Press; 2007.

6. Ananth CV, Joseph KS, Oyelese $Y$, Demissie K, Vintzileos AM. Trends in preterm birth and perinatal mortality among singletons: United States, 1989 through 2000. Obstet Gynecol 2005;105:1084-91.

7. Kramer MR, Hogue CR. What causes racial disparities in very preterm birth? A biosocial perspective. Epidemiol Rev 2009;31:84-98.

8. Menon R. Spontaneous preterm birth, a clinical dilemma: etiologic, pathophysiologic and genetic heterogeneities and racial disparity. Acta Obstet Gynecol Scand 2008;87:590-600.

9. Osypuk TL, Acevedo-Garcia D. Are racial disparities in preterm birth larger in hypersegregated areas? Am J Epidemiol 2008;167: 1295-304.

10. Porter TF, Fraser AM, Hunter CY, Ward RH, Varner MW. The risk of preterm birth across generations. Obstet Gynecol 1997;90:63-7.

11. Boivin A, Luo ZC, Audibert F, et al. Risk for preterm and very preterm delivery in women who were born preterm. Obstet Gynecol 2015;125:1177-84.

12. Swamy GK, Ostbye T, Skjaerven R. Association of preterm birth with long-term survival, reproduction, and next-generation preterm birth. JAMA 2008;299:1429-36.

13. Wilcox AJ, Skjaerven R, Lie RT. Familial patterns of preterm delivery: maternal and fetal contributions. Am J Epidemiol 2008;167:474-9. 14. Bhattacharya S, Raja EA, Mirazo ER, et al. Inherited predisposition to spontaneous preterm delivery. Obstet Gynecol 2010;115:1125-33.

15. Klebanoff MA, Schulsinger C, Mednick BR, Secher NJ. Preterm and small-for-gestationalage birth across generations. Am J Obstet Gynecol 1997;176:521-6.

16. Selling KE, Carstensen J, Finnstrom $O$, Sydsjo G. Intergenerational effects of preterm birth and reduced intrauterine growth: a population-based study of Swedish motheroffspring pairs. BJOG 2006;113:430-40.

17. Ncube CN, Enquobahrie DA, Burke JG, YeF, Marx J, Allbert SM. Transgenerational transmission of preterm birth risk: the role of race and generational socio-economic neighborhood context. Matern Child Health J 2017;13:1-11.

18. Foster HW, Wu L, Bracken MB, Semenya K, Thomas J, Thomas J. Intergenerational effects of high socioeconomic status on low birthweight and preterm birth in African Americans. J Natl Med Assoc 2000;92:213-21.

19. Castrillio SM, Rankin KM, David RJ, Collins JW Jr. Small-for-gestational age and preterm birth across generations: a populationbased study of Illinois births. Matern Child Health J 2014;18:2456-64.

20. Klebanoff MA, Zemel BS, Buka S, Zierler S. Long-term follow-up of participants in the
Collaborative Perinatal Project: tracking the next generation. Paediatr Perinat Epidemiol 1998;12: 334-46.

21. Davidoff MJ, Dias $T$, Damus $K$, et al. Changes in the gestational age distribution among US singleton births: impact on rates of late preterm birth, 1992 to 2002. Semin Perinatol 2006;30:8-15.

22. Alexander GR, Kogan M, Himes JH, Mor JM, Goldenberg R. Racial differences in birthweight for gestational age and infant mortality in extremely-low-risk US populations. Paediatr Perinat Epidemiol 1999;13:205-17.

23. Chapman DA, Gray G. Developing a maternally linked birth dataset to study the generational recurrence of low birthweight in Virginia. Matern Child Health J 2014;18:488-96.

24. Emanuel I, Leisenring W, Williams MA, et al. The Washington State Intergenerational Study of Birth Outcomes: methodology and some comparisons of maternal birthweight and infant birthweight and gestation in four ethnic groups. Paediatr Perinat Epidemiol 1999;13:352-68.

25. Spong CY, Mercer BM, D'Alton M, Kilpatrick S, Blackwell S, Saade G. Timing of indicated late-preterm and early-term birth. Obstet Gynecol 2011;118:323.

26. Siu SC, Sermer M, Colman JM, et al. Prospective multicenter study of pregnancy outcomes in women with heart disease. Circulation 2001;104:515-21.

27. Ananth CV, Vintzileos AM. Maternal-fetal conditions necessitating a medical intervention resulting in preterm birth. Am J Obstet Gynecol 2006; 195:1557-63.

28. Hou S. Pregnancy in chronic renal insufficiency and end-stage renal disease. Am J Kidney Dis 1999;33:235-52.

29. Esplin MS, O’Brien E, Fraser A, et al. Estimating recurrence of spontaneous preterm delivery. Obstet Gynecol 2008;112:516-23.

30. Plunkett J, Borecki I, Morgan T, Stamilio D, Muglia LJ. Population-based estimate of sibling risk for preterm birth, preterm premature rupture of membranes, placental abruption and preeclampsia. BMC Genet 2008;9:44.

31. Reichman NE, Schwartz-Soicher O. Accuracy of birth certificate data by risk factors and outcomes: analysis of data from New Jersey. Am J Obstet Gynecol 2007;197:32.e1-8.

32. DiGiuseppe DL, Aron DC, Ranbom L, Harper DL, Rosenthal GE. Reliability of birth certificate data: a multi-hospital comparison to medical records information. Matern Child Health J 2002;6:169-79.

33. Dobie SA, Baldwin L-M, Rosenblatt RA, Fordyce MA, Andrilla CHA, Hart LG. How well do birth certificates describe the pregnancies they report? The Washington State experience with low-risk pregnancies. Matern Child Health J 1998;2:145-54.

34. Zollinger TW, Przybylski MJ, Gamache RE. Reliability of Indiana birth certificate data compared to medical records. Ann Epidemiol 2006:16:1-10.
35. Torloni MR, Betran AP, Daher S, et al. Maternal BMI and preterm birth: a systematic review of the literature with meta-analysis. $\checkmark$ Matern Fetal Neonatal Med 2009;22: 957-70.

36. Blencowe H, Cousens S, Oestergaard MZ, et al. National, regional, and worldwide estimates of preterm birth rates in the year 2010 with time trends since 1990 for selected countries: a systematic analysis and implications. Lancet 2012;379:2162-72.

37. Cnattingius S, Villamor E, Johansson S, et al. Maternal obesity and risk of preterm delivery. JAMA 2013;309:2362-70.

38. Menacker F, Martin JA. Expanded health data from the new birth certificate, 2005. Natl Vital Stat Rep 2008;56:1-24.

39. Klebanoff MA, Yossef-Salameh L, Latimer C, et al. Development and validation of an algorithm to determine spontaneous versus providerinitiated preterm birth in US vital records. Paediatr Perinat Epidemiol 2016;30:134-40.

40. Stout MJ, Busam R, Macones GA, Tuuli MG. Spontaneous and indicated preterm birth subtypes: interobserver agreement and accuracy of classification. Am J Obstet Gynecol 2014;211: 530.e1-4.

41. Stout MJ, Macones GA, Tuuli MG. Accuracy of birth certificate data for classifying preterm birth. Paediatr Perinat Epidemiol 2017;31: 245-9.

42. Martin JA, Hamilton BE, Sutton PD, et al. Births: final data for 2005. Natl Vital Stat Rep 2007:56:1-103.

43. Parets SE, Conneely KN, Kilaru V, Menon R, Smith AK. DNA methylation provides insight into intergenerational risk for preterm birth in African Americans. Epigenetics 2015;10:784-92.

44. Kramer MR, Hogue CJ, Dunlop AL, Menon R. Preconceptional stress and racial disparities in preterm birth: an overview. Acta Obstet Gynecol Scand 2011;90:1307-16.

\section{Author and article information}

From the Division of Maternal Fetal Medicine, Department of Obstetrics and Gynecology (Drs Smid, Grant, and Manuck), and Department of Epidemiology (Ms Miles), University of North Carolina-Chapel Hill, Chapel Hill, NC; Division of Maternal Fetal Medicine, Department of Obstetrics and Gynecology (Dr Smid), and Division of Epidemiology, Department of Internal Medicine (Mr Stoddard), University of Utah, Salt Lake City, UT; and Division of Epidemiology, Department of Family Medicine and Population Health, Virginia Commonwealth University, Richmond, VA (Mr Lee and Dr Chapman).

Received March 3, 2017; revised May 16, 2017 ; accepted May 22, 2017.

The authors report no conflict of interest.

Presented as posters (final abstract 532 and 533) at the 37th annual meeting-the pregnancy meeting of the Society for Maternal-Fetal Medicine, Las Vegas, NV, Jan. 23-28, 2017.

Corresponding author: Marcela C. Smid, MD, MA, MS Marcela.Smid@hsc.utah.edu 